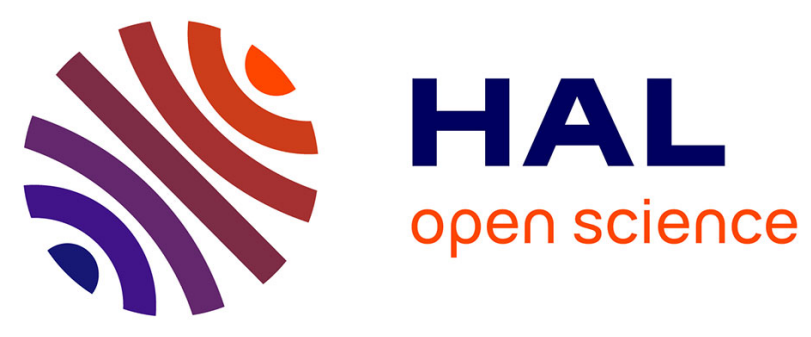

\title{
Study case: Living Lab Mode for urban project design: Emergence of an ad hoc methodology through collaborative innovation
}

Laurent Dupont, Laure Morel, Julien Hubert, Claudine Guidat

\section{- To cite this version:}

Laurent Dupont, Laure Morel, Julien Hubert, Claudine Guidat. Study case: Living Lab Mode for urban project design: Emergence of an ad hoc methodology through collaborative innovation. 2014 International Conference on Engineering, Technology and Innovation (ICE), Jun 2014, Bergamo, Italy. 10.1109/ICE.2014.6871550 . hal-01332260

\section{HAL Id: hal-01332260 https://hal.science/hal-01332260}

Submitted on 15 Jun 2016

HAL is a multi-disciplinary open access archive for the deposit and dissemination of scientific research documents, whether they are published or not. The documents may come from teaching and research institutions in France or abroad, or from public or private research centers.
L'archive ouverte pluridisciplinaire HAL, est destinée au dépôt et à la diffusion de documents scientifiques de niveau recherche, publiés ou non, émanant des établissements d'enseignement et de recherche français ou étrangers, des laboratoires publics ou privés. 


\title{
Study case: Living Lab Mode for urban project design*
}

\author{
Emergence of an ad hoc methodology through collaborative innovation
}

\author{
Laurent Dupont, Laure Morel, Julien Hubert, Claudine Guidat \\ ERPI - Equipe de Recherche sur les Processus Inovatifs \\ Université de Lorraine \\ Nancy, France, \\ \{1.dupont, laure.morel, julien.hubert, claudine.guidat\}@univ-lorraine.fr
}

\begin{abstract}
Living Lab Mode for urban projects opens various fields of investigation for urban project management and Living Lab methodology. Using a three year-experiment on co-designing an eco-neighborhood, this study case contributes to examine the specificity of long-term user-oriented project management. Furthermore, the study describes the development of a method to implement a project in Living Lab Mode. Finally, the research underlines the mutual contribution between participatory process and co-design process in an urban project.
\end{abstract}

Keywords-Living lab, urban project, co-design, users, participatory process

\section{INTRODUCTION}

Living Lab concept remains relatively recent. Former studies [1]-[4] design the conceptual framework of this new approach, which put users into the center of value creation for companies, or for the Society. The variety of applications could provoke criticisms (fuzzy concept, new name used for former tools and methodologies). At present, Living Lab Research seems more organized and the diversity and rich production allows to define an outlined agenda [5]. Specific cases of Living Lab operation shows the diversity of innovation activities associated with Living Labs, and more experimentation and studies are expected to unveil phenomenological diversity.

In specific situation, Living Lab concept is adopted to analyze or develop projects or models for cities, territories and regions. For example, recent works intend to analyze and identify boundary conditions for successful Urban Living Labs [6], [7]. These researches offer guidelines to define and establish an Urban Living Lab.

This paper exposes a case of Living Lab operation in the urban field and its original findings. This contribution is based on experimentation of quite three years (between 2011 and 2013) situated in the confluence between the Engineer Sciences (Industrial engineering) and the Human and Social Sciences (Sociology, Political sciences). Different studies, which mobilized sociologists, researchers on innovative process, architects, town planners, political specialists, are now connected to demonstrate how an eco-neighborhood project and its eco-mobility challenge can be used as case study to illustrate, analyze and expose new operational and scientific findings for the co-design of urban projects. Besides, contributions on Living lab methodologies in urban context are suggested.

This original multidisciplinary approach, applied on urban project management, is an extensive scientific answer to a territorial issue: organized and estimated the engineering of the participatory process, which accompanies the project of Econeighborhood "Nancy Grand Cœur". The urban project is designed around the train station of Nancy (East of France) since 2008. The scientific project comes from the convergence between a local expectation from technicians and elected representatives, a national requirement (official bill of specifications for eco-neighborhood) and a research team's wishes interested in Living Lab researches. To support this research project, the Lorraine Smart Cities Living Lab, developed by ERPI laboratory and recognized by ENoLL in 2010, was mobilized (financial and human resources).

It is an obvious fact to distinguish urban ecosystem and companies, e.g.: urban projects are longer than industrial projects; in cities, representatives are democratically elected and local decision-makers have to think carefully about multitude of interconnected parameters; firms target her energies towards specific end-user while cities have to consider all the different users. How to develop user-centric approach or user-driven approach when the usages and users are so different, even unknown? How to consider using feedback when every decision can potentially impact urban area and block for a long time? Finally, how to collaborate with users when they do not already exist?

In Nancy's case, the research team considers the participatory process of the eco-neighborhood project as a part of a living lab process. In other words, we talk about urban project in Living Lab mode and we adapt some methodologies connected to Living Lab concept as user-centric design or collaborative innovation. This scientific position gives the opportunity to read through a different paradigm the urban project management, specifically the design process in the urban project management. Thus, the originality of the research is to transform territorial issue into scientific issue supported by a technological transfer from industrial field to urban field. 


\section{RELATION TO EXISTING THEORIES AND WORK}

\section{A. From industrial design to urban co-design}

Reference [8] shows that in urban project management in developed countries, it is more and more admitted that make professionals of urban issues collaborate and understand endusages of an urban project allow to take better strategic decisions (particularly in sustainable and economic perspectives). Despite that, during the initial stage of the design process, the citizen participation remains weak. Most often, due to regulation and habits, consultation is chosen. End-users are just questioning during the design process or sometime later, during the development process (when the urban project is being built). For this mode, we talk about classic urban project management. Citizens (residents, shopkeepers, travellers, pedestrians, driver, etc.) and local authority's technicians or experts are widely separated. Urban design process does not favor easily interconnections between usage experts and decision-makers.

During the urban project management, associate users deeply transforms the design process as suggested in Living Lab research Landscape [9]. Indeed, previous industrial oriented researches can help to formulate and conceptualize the difference between "classic" design and co-design of urban projects. Here, co-design means collaborative design between technicians and users. To illustrate, in industrial project management, organizing test-bed and prototypes is considered as "evaluation", users are observed subjects while co-design needs a real and active participation of user as soon as possible. In this case, users are admitted as value creation and the process is more open (Open innovation, collaborative innovation).

A similar problem of change management in the industrial and urban fields is observed. It allows to set up and to test a Living Lab approach for urban project design, in association with an Urban Community (Grand Nancy). This innovative local approach generates a new point of view on urban project management.

\section{B. Living Lab mode: a distributed collaborative approach}

The context of the Living Lab operation is very specific. In a sustainable city perspective, an eco-neighborhood is designed. The first sustainable stake, identified by townplanners and urban decision-makers is to develop sustainable mobility (eco-mobility) with the train station as urban hub in the center of this agglomeration of 250000 inhabitants. Furthermore, the station generates 3 million travellers per year. Sustainable stakes generate many factors to take into consideration, such as new buildings, new streets, new users. In this complexity, one of the main objectives was to co-design systems, projects or products to generate eco-mobility in the area of Nancy. Eco-neighborhood is an opportunity to mobilize citizens around eco-mobility. To tackle mobility issue means identify and take into account the diversity of factors, actors and usages. Public and private transportations, as well as

* Université de Loraine (ex-INPL), DIRECCTE and FEDER supported "La Fabrique" experimentation (through Lorraine Smart Cities living lab project, 2010-2011). Conceptualization, analyze process and capitalization is supported by French national research program (Ministry of Sustainable Development, 2008-2012) and Grand Nancy. motorized and human or real and virtual mobility have to be considered. Behind that, budgets, town planning, regulations, Information and Communication Technologies (ICT) evolution force or lead to adopt or transform solutions. To sum up, for mobility topic, various usages, and users with different expectations, have to be combined. A Living Lab mode aims precisely to get together these users' perspectives: it focuses on usage expertise, so that citizens do not need technical knowledge or other specific expertise to take an active part in the project, and favors co-design of urban project.

Let us underline that Living Lab concept emerged from an urban context: at the beginning of the 2000s, William Mitchell, Architect and Professor at MIT, imagine that living environment (buildings, cities, etc.) can be laboratories were to make experiments and work on real data. ICT allow being reactive to the cities and their context (economy, energy, etc.) shifts [10]. In this study case, independently of ICT, the user is considered as a potential active actor of the urban design process. ICT interface can support this potential. Living Lab concept arises a democratic dynamic, and blows the hope of extensive participation.

Considered as an ecosystem of mediation, Living Lab is a facilitator between classic public and private partners (Agencies, Companies, Researchers, etc.) and users' communities [11]. To assume this ambition for eco-mobility, researchers on urban co-design imagine and implement a distributed collaborative design process. It allows at less to cross-reference information from all local stakeholders of mobility for sustainable development. From an ideal point of view, the purpose of this process is to create spaces and times to make these stakeholders work together. Furthermore, it is required to have a shared vocabulary and knowledge.

Moreover, systemic consideration (sustainability) leads to consider that Eco-Neighborhood context (history, geography, economy, social dimension, etc.), future developments and societal shifts strongly impact actual and next usages. In other words, to tackle mobility issue, it is necessary to have a wider vision and to make connections with other urban topics.

Several previous studies on "Nancy Grand Cœur", described in articles, communications or research reports show the first contributions of our experiments at various levels. This paper uses these previous scientific productions to generate a global vision of the co-design process of the urban project. The purpose is to reveal the framework for urban projects management through Living Lab mode. Five previous and meaningful contributions are summarized in chronological order. For every following study is specified the nature of the contribution (CC for conceptual or OC for operational).

1- CC: Reference [12] proposes a theoretical collaborative space. This scientific object can support "citizens panels" to improve participatory process in the initial stage of urban project and reduce the time of urban project. Due to the originality of this space model, the paper concludes that it would be relevant to organize an iterative process to experiment and improve by use this collaborative space. 
2- OC: Reference [13] capitalizes 6 months of "La Fabrique" experimentation (workshops of the econeighborhood "Nancy Grand Coeur" participatory process) realized in 2011 (see $\S \mathrm{III}$ ) and shows, though 26 scientific interviews (citizens, technicians, animators) among 180 mobilized persons, the specific role of the technicians from the local authority in the success of this participatory process and the valorization of usage expertise.

3- CC: Reference [8] conceptualizes a distributed collaborative urban ecosystem generated by collaborative space and distributed collaborative process. This work gives conceptual framework to rethink urban project management in Living lab mode, and establishes a model for co-design.

4- OC: Reference [10], based on the analyze of a huge questionnaire conduct in June 2011 at the end of "La Fabrique" participatory process, compares "La Fabrique" experimentation and the collaborative space theoretical model (see point 1 above) and shows in urban project co-design context that stakeholders' mobilization, transparency and reasoning in terms of uses are difficult to realize due to the political sphere, and the difficulty to anticipate the future usages in econeighborhood.

5- CC \& OC: [14] analyze how serious-gaming could improve co-design process. Putting participants into action favor the learning process and shared knowledge. It is particularly relevant for complex issues as sustainable development. Researchers illustrate their thought by the analysis of a prototype of serious-game on the eco-mobility. This game, a student project, was developed in partnership with ERDF (French distributor of electricity and at the origin of the project). In this study case of 2012, it was proposed to implement virtually eco-mobility in the suburbs of Nancy. Forty persons participated (industrials, elected, users, local authority's technicians), fifteen of them were directly mobilized by the eco-neighborhood project. This experience gives them an "open-minded" eco-neighborhood approach.

The state of the art, the previous studies and the first scientific capitalizations give the raw material to describe a long experimental process involving users and implemented in real world. Furthermore, we can report some impacts of this innovative process on the ecosystem of experiment.

\section{RESEARCH APPROACH}

\section{A. Principle and main steps of the research}

Eco-neighborhood project is an urban and human system. Many aspects of this system can be observed and studied. They are different scientific ways of understanding what is going on, as exposed on the previous section with CC \& OC. Study and work with this kind of topic involve adopting particular perspective and values, and these in turn determine what aspects of the situation we understand as being part of the system of our concern. Due to the proactive nature of this work, action-research methodology [15] was adopted. The paper develops the four following steps of the research process:
1- the research team identifies and defines precisely the operational problem situation by a strong involvement in the urban design process (see§B.1).

2- the research team formulates the boundaries of the relevant ecosystem to investigate. The frontiers are determined by the interaction between literature, the real world immersion and the previous researches. These elements give several axes of investigation and the conceptual material to interpret the results (see $\S$ B.2).

3- the involvement of research team in the real world allows comparing the models with the reality and observing actors' behaviors and ecosystem's shifts. For this step, the capitalization of observable facts and the multiplicity of sources are fundamental to give exploitable data and evaluate the situation (See $\S C, D, E$.)

4- the research-action highlights the changes that are desirable and feasible in the ecosystem. The research team can take action to improve the real world situation and conclude with acquired operational and scientific knowledge (Read §IV).

The action-research method is an iterative process. The four steps are not sequential. The steps feed mutually and a perpetual interaction between the theory and the practice strengthens the research approach. In the next section, the paper exposes the observations and analyzes the ecosystem generate by this cyclic approach.

\section{B. Studied system and issue}

\section{1) Problem situation}

The research team accompanied the design, the animation, the observation and the analysis of the eco-neighborhood participatory process and its associated main device: a collaborative space. Thus, with this operational level, this project, named "La Fabrique Nancy Grand Coeur" aims to:

- Put into the urban project design the users and citizens points of views

- Mix expert and usage knowledge

- Favor shared diagnosis and co-design

- $\quad$ Bring to the foreground innovative ideas via creative initiatives

- Organize an acculturation space

The operational level is necessary but not sufficient to allow the local authority' technicians to learn new skills and develop new urban design approaches. Thus, as describe in our operational and conceptual contributions [8], [10], [12]-[14], the research team lead the experimentation to achieve three more global impacts which are on the organizational (tactical) plan:

\section{- $\quad$ Promoting the Citizens' Knowledge}

- Assuring a design of the eco-neighborhood project based on the diagnosis of usages

- $\quad$ Generating a distributed collaborative design process between territory stakeholders 
Draft - Publised version available at: Dupont L., Morel L., Hubert J., Guidat C., Study case: Living Lab Mode for urban project design. Emergence of an ad hoc methodology through collaborative innovation.

IEEE 20th ICE-International Conference on Concurrent Enterprising, Bergamo, Italy, 23-25 june 2014 http://ieeexplore.ieee.org/lpdocs/epic03/wrapper.htm?arnumber=6871550

\section{2) Considered ecosystem and human activity system}

Due to the problem situation, a multidisciplinary team is mobilized. Industrial Engineering allows conceptualizing the development of the project on Living Lab mode. Social Sciences help to implement the co-design of the urban project. Furthermore, research team works closely with some local authority's decision-makers. Thus, fifteen experts and specialists were connected and worked together to develop an important participatory process (numerous participants). Take only usages into account and involve users are two different processes. The second option means developing a collaborative process in the urban field where individual objectives and usages are strongly different. The research wants to understand how the participatory process makes the condition to generate a global co-design process with urban users (citizens, technicians of the local authorities, enterprises), and mutually. Precisely, the scientific objective is to explain the iterative development of a method to implement a project in Living Lab mode and the "impacts" on the ecosystem. "Impacts" mean the effects and new scientific issues and hypothesis.

To understand the potential evolution of the ecosystem the research team built the "conceptual models of human activity systems" based on the four following postulates:

1. In Co-design, usage is thought as "issues-integrator". For research team, adopting usage approach allows to consider all the different stakeholders (from usages to the connected actors). For the different stakeholders, adopting a "usage point of view", can help to change the project vision.

2. Living Lab mode for urban project management can adopt a distributed collaborative design process: in urban project, knowledge is distributed between actors, by space and time. Especially usage is considered as source of original knowledge. Furthermore, distributed collaborative design gives strategies to tackle space, time, technological, and cultural barriers [8].

3. Considering actors and projects in their ecosystem: the sustainable development paradigm invites us to link Humanity and its environment. Citizens are strongly linked to the rhythm and the organization of the city where they live, and reciprocally.

4. The technicians of local authority are considered as users in the co-design process. It is particularly relevant when they are involved in a collaborative innovation, a user-centric approach, or even a user-driven approach. Furthermore the research team has to assist the technicians to work with these recently transferred methodologies in their ecosystem.

The experimentation focuses on these four axes of investigation through a three years research-action process. During this period, tools as observation, interviews, survey, investigation, modeled process, iterative process, etc. were used to capitalize and analyze the developed co-design process. The sections III.C and III.D describe the implementation and the obtained operational outputs.

\section{1st year: eco-neighbourhood global approach and diagnoses of usages}

\section{1) Methodology: iterative citizens panels}

Concretely, the approach mobilized 180 diversified participants (organized and not organized inhabitants, Technicians of local authorities, Elected representatives, experts from companies, State services, etc.) among which 130 persons in 19 workshops ( 1 or 2 per week for 6 months), in the first half of the year 2011 .

Workshops are adapted from "citizens panels" model. Group of users is put into simulation and expressions of usages are observed and recorded (Fig. 1). This process is repeated for every workshop.

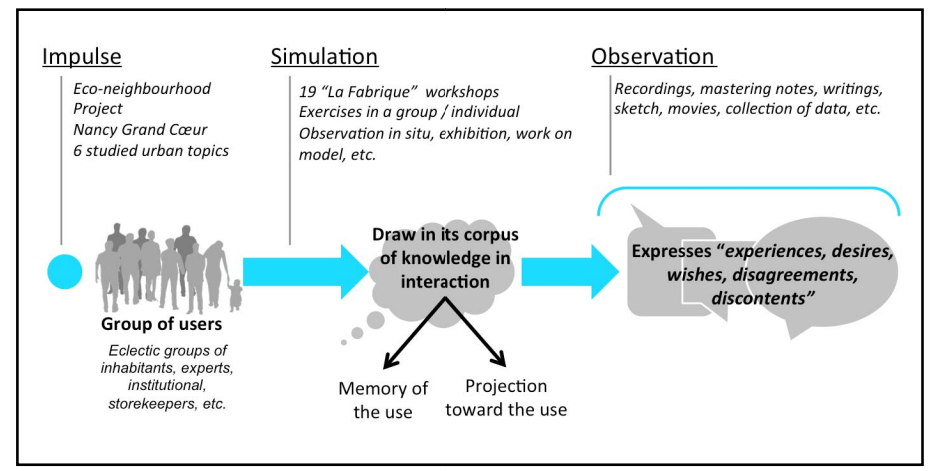

Fig. 1. "Citizens panels" model adapted to "La fabrique" workshop - Our research, 2012 adapted from [16]

Six topics were explored to describe and reveal many aspects of potential use: "Living environment, urban practices and territorial identity", "Citizen sustainable mobility", "Better together life and urban diversity", "Strengthening of the coherence between three ages of the city", "Green building and Environmental quality", "Economic and social development balanced within a common culture". A transversal subject was added "Experimental block and public spaces" to develop links between the six other topics.

Every workshop supposes to be prepared with technicians and experts of the thematic considered. The objective is to give relevant information to participants and allow them to contribute to a realist framework. The meetings consist of moments of common display then moments of diversified groups working in logic of brainstorming using stimuli (videos, mock-up, plans, photos, diagrams, keywords, etc.).

After the "citizens panels", all the expression of the participants are collected and analyzed. If necessary some elements are compared and verified to literature or to the technicians of the local authority. Thus, through a cross analysis of qualitative data, collected during the exchanges in workshop, usage expertise interacts with other elements coming from the different experts (Survey report, research paper, additional scientific interviews, etc.).

If a researcher in the innovative urban process engineering manages the global "la Fabrique" process, in contrast a sociologist $(\mathrm{PhD})$ and his colleagues (one sociologist and one architect) drive all the "workshops" stage. To summarize, main 
Draft - Publised version available at: Dupont L., Morel L., Hubert J., Guidat C., Study case: Living Lab Mode for urban project design. Emergence of an ad hoc methodology through collaborative innovation.

IEEE 20th ICE-International Conference on Concurrent Enterprising, Bergamo, Italy, 23-25 june 2014 http://ieeexplore.ieee.org/lpdocs/epic03/wrapper.htm?arnumber $=6871550$

used tools and methodologies used are collaborative environments and sociologist interventions (among which citizens panels, interviews of experts, technicians or organized users, state of art, etc.). The research team used exploring methods in collaborative environments.

\section{2) Operational outputs: building a new generic process}

a) "La Fabrique" outputs after one year of experimentation (end of 2011)

The centralization, analysis and shaping of the elements of diagnosis produce an oriented social science diagnosis of the eco-neighborhood project.

The research team organized with decision-makers and technicians: In June 2011, one temporary restitution to the workshops' participants and delivered seven public booklets, describing the first analyses and main expected usages. Later, in December 2011, two public restitutions (dedicated to expected mobility and global expected usages and econeighborhood project' meaning) were made to the Council of governance and to the participants. Plus, two exhaustive diagnoses of usages (mobility, global usages) and syntheses (technical documents) were delivered to decision-makers of local authority and to the town-planners.

\section{b) “La Fabrique" scientific observations [13]}

Globally, participatory process is really appreciated by technicians and representatives. Thanks to the workshops process and the capitalization of usages in the diagnoses of usages the citizens' knowledge is promoted. Furthermore, both political and technical actors expressed their willing to pursue the participatory process.

But it is also observed, after one year of experimentation, that only the first organizational purpose is completed. One year of project does not allow assuring a design of the econeighborhood project based on the diagnosis of usages and the generation of a distributed collaborative design process between territory stakeholders.

If researchers have knowledge (diagnosis, participatory process and collaborative engineering) in possession and significant operational results, they cannot assess the global impact on urban project management. It is possible irreversible shifts were engaged for the design process of the urban project. While, stopping the experience after one year does not guarantee the expected professional behavior evolution. For example, how to allow the appropriation of the diagnoses of usage and the urban project management (co-design)? If the repetition of the citizens panels model with "La Fabrique" Workshops gives some results we can conclude that this process is useful but is not sufficient for new urban projects management.

\section{c) a new experimental impulsion}

The global scientific process was enhancing. Experience and collaborative innovative engineering approaches suggest adopting and evaluate the new following generic process, Fig.2:

- $\quad$ 1st step: Diagnosis (of usages)

○ Reading the territory

\section{○ Crossing knowledge \\ ○ Identifying expectations and needs}

- 2nd step: Integration of usages' expectations in urban project design
○ Focusing \& Deepening
○ Ranking
○ Making functional scenarios

- 3rd step: Consolidation of designed solutions with users
○ Testing
○ Making strong
○ Adjusting the implementation

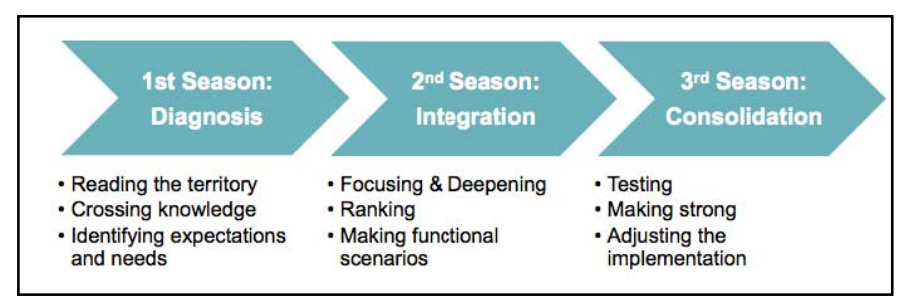

Fig. 2. Generic process of co-design suggested by "La Fabrique" experience (Adpated from [13])

This process gives the new framework of the academic and local-authority' technicians collaboration (contract of three years 2012-2014 to take into account the necessary 1 or 1,5 year to realize each step). Considering the enthusiasm of the actors, it was decided to speak about seasons.

This new model allows pursuing the eco-neighborhood codesign experimentation. In the next section, operational implementation is briefly exposed.

\section{2nd and 3rd season: implement co-design process of the urban project, eco-mobility as study case}

\section{1) Second season: toward co-design process}

During 2nd season a double strategic was lead to make concrete co-design concept and act on the Eco-Neighborhood: focus on a place and focus on a topic.

\section{a) Focus on a place}

The renovation at Nancy of the Charles III square and its underground parking give the opportunity to experiment ecomobility, particularly through the design of mobility stations.

Firstly was generated a "usage point of view" in the renovation of Charles III Square process. Thus, on the first quarter 2012, was organized and observed four "La Fabrique" workshops dedicated to this space close to eco-neighborhood. The urban project in the historical downtown has to articulate: Heritage aspect because it is a historic site; Mobility flows and the intermodal connections of the site: pedestrian, public 
transit, accessibility to parking area located under the square; Commercial dynamism: a large commercial center and a covered market surround renovated space taken by café terraces; Public safety; Urban entertainment and downtown events.

Offering several moments/places/tools/methods of interaction and interlinked actors to co-design some aspects of the city square created a participatory dynamic not yet realized, in spite of the advanced character of the project. It is important to underline that this participative process was introduced at the time of the arbitration of some technical choices. Therefore all the actors had a clear understanding of the possibilities (economical, technical, environmental, etc.) as well as everyone strengthened this final project. In fact, VINCI, a construction group, had already designed a mobility station. "La Fabrique" allowed integrating nevertheless the logic of use, which have not been anticipated. Decision-makers of Nancy organized the collaboration with the company in the leeway of the official public market.

The four observed workshops included a panel of 35 persons representing the diversity of all the urban project stakeholders. Only one meeting was exclusively and voluntarily including elected representatives and technicians. These aimed to share the territories challenges and to identify the complex or sensitive elements from which specific solutions could be given. Contrary to "La Fabrique" workshops, the authority's technicians managed these meetings and were advised by team research. However, researchers explored the productions and proposed an analysis leant on the observation of the groups, the capitalization of various elements mentioned during Charles III workshops, and especially by making the link with the diagnosis of usages got in the 1st "La Fabrique" season. As shows the following map the eco-neighborhood "Nancy Grand Cœur" becomes a school neighborhood: expected eco-mobility usages identify are transposed on renovated Charles III square, Fig.3.

b) Focus on the topic: eco-mobility and mobility stations

Grand Nancy's technicians and researchers organize into a hierarchy of the elements relating to eco-mobility and mobility stations. Then researchers rewrote diagnosis of usage in a four parts tab: 1) "stakeholder use requirements", 2) linked tasks done or scheduled, 3) reason for not acting, 4) (potential) mobilized stakeholders. This new document, based on identified "stakeholder use requirements", allowed interviewing six local experts and defining potential expected functions of a generic mobility stations.

To conclude, in 2nd season main tools and methodologies used are collaborative environments with citizens and technician and engineering process with mobility' experts, local authority's technicians and elected representative. With the formalization of a generic mobility stations the research team (innovative engineering researchers and sociologist) impulse co-design process with technical and political decision-makers. Diagnosis of usages from eco-neighborhood project is integrated in the city under construction. And concretely, with Charles III square study case, usage expertise improves the initial project when changes can be done. If the project cannot change during the construction, potential difficulties of use can be anticipated and solutions can be imagined earlier.

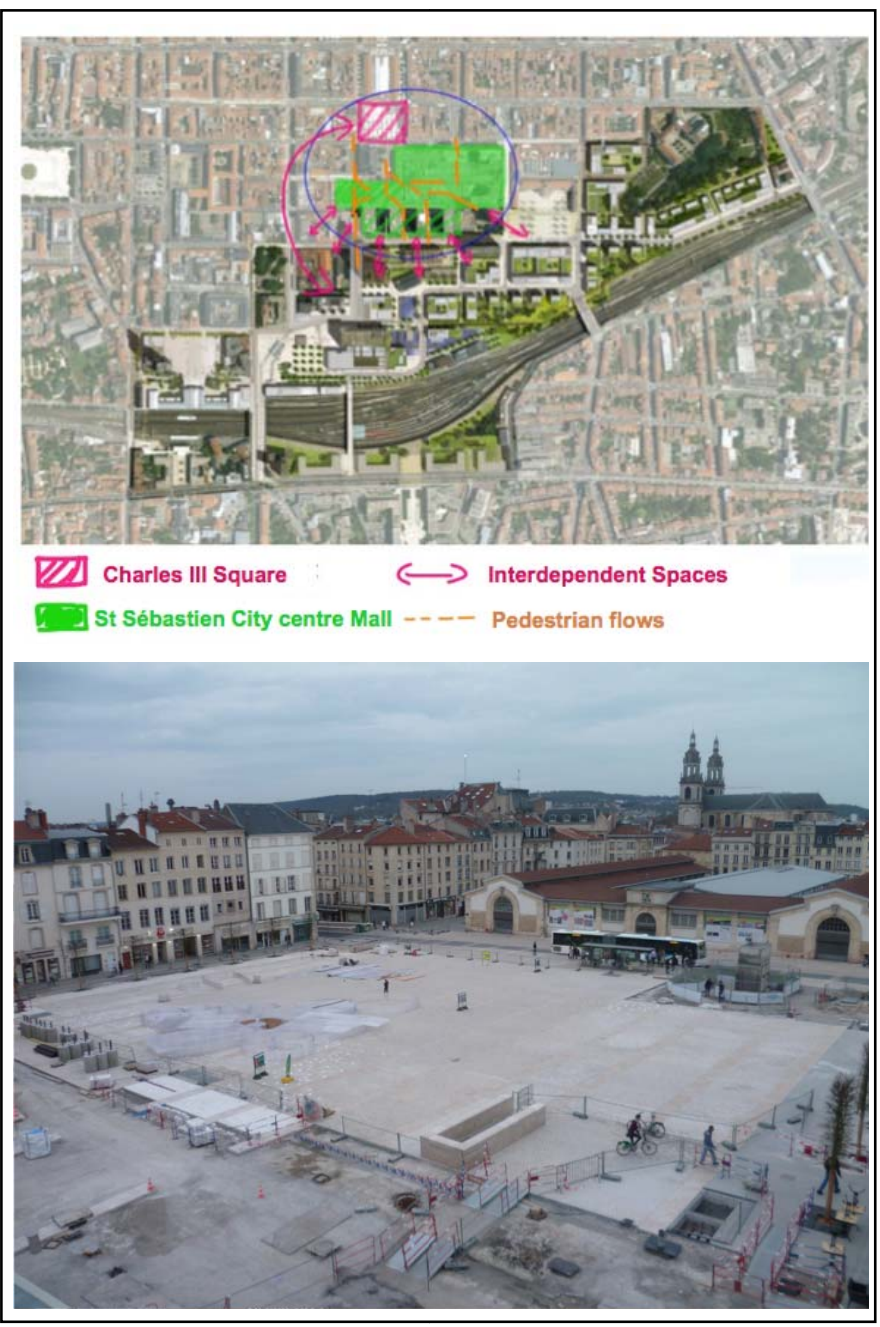

Fig. 3. Links between Eco-Neighborhood and Charles III Square - View of the renovation [13]

\section{2) Third season: release urban co-design process}

For the last season of the study case, users (citizens and technicians) were invited to participate in two special "La Fabrique" workshops set up with an original scenography about the physical organization of Charles III mobility station and the generic aspects of eco-mobility stations Fig.4 based on:

- VINCI station mobility blueprints exhibition,

- Scale-modeling: it is a mock-up with a scale really inferior to the real size. Its realization was supported by Fab Lab technologies (from GSI Lab connected to ERPI Laboratory.)

- Body-storming sessions: in a real dimensions room (real scale) users can generate and test many contextand behavior-based concepts by physical enactment.

- City map localization: to identify pertinent places to implant mobility stations. 


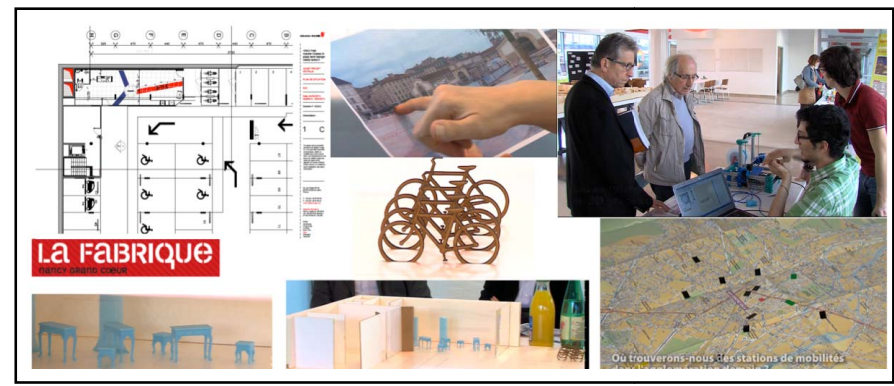

Fig. 4. Original scenography about the physical organization of Charles III mobility station (2013)

The mock-up elements and the room elements are the same, with different scales: chairs, tables, displays, and pieces of paper. (These technologies and experimentations will be widely described in an incoming scientific paper [17].) Concurrently with these studies, a sociologist leads a global sociology study on use of mobility in area of Nancy.

With physical representations and first usages tests, this season materializes and evaluates results from the previous season. Furthermore, the proposals of adjustment of the programed implementation consolidate the urban project design.

\section{E. A methodology stemming from the use}

"La Fabrique" project began with huge citizen participation and generated of shared diagnosis of usages of the EcoNeighborhood (Year 2011). After this first step, the team research worked with technicians and town-planners to imagine a "global eco-mobility system" adapted to local urban context (social, economic, geographical, etc. aspects). The year 2012 was dedicated to this second step with a strong analysis of the requirements, based on needed usages. Citizen participation was kept with a mobilization on parallel urban project (Charles III square). Finally, users were associated to the materialization and adjustment of the functions of a generic mobility station and its localization.

Our study case, observed during a long period, clearly embraces a large variety of involvements of use and users in the co-design process of the urban project. The econeighborhood project in Living Lab mode is possible, as our operational contributions on mobility shown, from diagnosis of usage to experimentation of co-created solution.

Some methods and postures from industrial environment are adapted and shared with actors of the local ecosystem. In the logic of distributed collaborative design adapted to urban project [8], a technological transfer is engaged and necessary modifications are proposed. In this way, an ad hoc engineering for participatory process (tools, methods, environment) and governance (stakeholders management) is developed. For urban design, Living Lab Mode seemed to be the choice and these new abilities to include users throughout the urban project.

Can the ad hoc methodology be adapted in other territory or can help to co-design other urban project from the same territory? In other words, how to reproduce this ad hoc methodology?
It seems the fundamental aspects of this methodology are linked to Human aspect. It is the work, the exchanges, and the interactions between all the actors concerned by "La Fabrique" project, which create these operational and scientific results. The research team needs the citizens and the technicians' participation despite times of stress and difficult situations. And the different scientific productions [8], [10], [12]-[14] show the benefit to the eco-neighborhood project and also for the local society. A collaborative innovation is produced by these frequent and global interactions and interweaving. In the last section, the human aspects are specified.

\section{FINDINGS}

To support the expected global organizational purposes (§III.B.1), a generic process resulting from the experience of the 1 st season was created. 2nd and 3rd seasons prove that initial engineering input takes by researcher is not sufficient to provoke a co-design process.

This apparent "cold approach" or engineering approach needs to be supported by a stakeholder management and a shift management. It is absolutely necessary to consider the human and soft factors. Social sciences give tools and methodology to make these desirable and feasible changes.

Indeed, after the 19 workshops, the analysis of 26 scientific interviews of participants and animators [13] and the interpretation of several technical meetings with localauthority' technicians (2nd and 3rd seasons) show two dimensions must be grasped concurrently to tackle societal stakes: continue the Participatory Process (PP) and strengthen the Co-Design Process (Co-DP). After the 1st season, for local actors "La Fabrique" must:

1.Assure transparency with citizens' knowledge (How these usages data are used? What consideration and decisions?) and Make appropriate diagnoses of usages (1st Saison results) by technicians and urban decision-makers

\section{Organize new citizens panels ("La Fabrique" Workshops)}

3.Increase and diversify mobilized actors (citizens, experts, technicians, etc.)

4.Analyse, strengthen, and add value to initial diagnoses,

5.Study feasibility of evocated solutions in diagnoses,

6.Help in the decision-making: identify shared functions and scenarios of usage

Objectives 1,2,3 seem more PP oriented while objectives 4,5,6 seem Co-DP oriented. In fact, these six propositions are deeply connected. E.g.: in industrial Co-DP, transparency is required. Thus, for territorial issues, the eco-neighborhood design experience confirms that it is essential.

The case study, observed between the half of 2010 and the end of 2012, allows to precise how the new generic process is strongly supported by Soft Skills - personality traits, goals, motivations, and preferences Fig.5. 


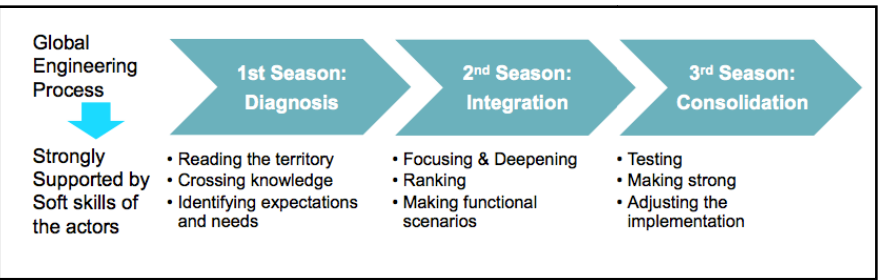

Fig. 5. Importance of the human factor in the Generic process of co-design suggested by "La Fabrique" experience (Adpated From [13])

In fact, the Co-DP of the urban project can be divided in two mains stage.

1) The initial stage is the Shared diagnosis, in which the promoters of the co-design have to: Gain the confidence of the users, technicians and others professionals; Identify and work with the early-adopters of the new approach (technicians), who will be prescribers; Prove the originality and new contributions in urban project management; Make of the mediation between different cultures and professions; Demonstrate that the codesign is an opportunity, and not a threat.

2) The second stage can be describe as From shared diagnosis to shared action, in which it is expected that the promotion team of co-design: Propose practical applications (a place and a short-time project); Continue workshops (because now it's known!) with huge and new panels; Spend time with the technicians on technical topics; Create new exercises to disrupt habits and generated new shared solutions; Shift the minds: urban project is not definitively built. We can experiment, transform and let decisions evolve with usage feedback.

It is important to underline that some tasks seem paradoxical: do the same kind of workshops when the urban project stage and the expected purposes are very different. Protocol to make a diagnosis of usage mobility should be different than to develop a new mobility service. But at the beginning it was difficult for the ecosystem to accept the PP and its workshops, due to the fear generated (possible citizen protestations or criticisms) [13]. For technicians and representatives, it appears relevant to reuse ingredients, which made the success of the 1 st season.

Otherwise, in the study case, time of the project allows to the research team to better understand local authority preferences, adopt the vocabulary and improve technological transfer (urban project designs in Living Lab Mode). Thus, season 2 and 3 are based on similar workshops to season 1 . The $\mathrm{PP}$ is stabilized and repeated to guarantee the Co-DP development. This strategy also gives the opportunity to repeat experimentation for a long period of time and study different factors.

\section{During the 1st season, Co-DP is:}

- Observing and listening to users and technicians (Citizens panels)

- Accompanying the project

- Being of assistance of the initial team

It's as if an outside team only supported the Co-DP. Actors meet around usage as "issue-integrator".
For 2nd season, Co-DP is supposed to:

- Give back to workshops' participants

- Make the technicians participate in the new process (give tools)

- Co-design with technicians

In this new step, technicians are strongly mobilized and asked. They have to integrate diagnosis of usage in the project and develop adapted solutions.

For the 3rd season, Co-DP comes back close to (potential) users. Workshops are developed to:

- Materialize concept from citizens panels in possible framework

- Co-design with technicians and users:

○ Favor appropriation

- Customize urban project if it is possible

Until the last step, the Co-DP is user-oriented. And some time, conditions are created to generate user-driven moments.

This subtle alchemy could seem fragile. But it is also its strength. We reveal the importance of human factors. The Living Lab mode is a new state of mind to design and develop urban project. To lead urban project co-design, reference[18] explains that "the importance of cognitive ability increases with the complexity of the task". Our study case is a relevant example. Urban projects designed in Living Lab Mode build up themself from the capacity of the actors to change the way they work, they position in the Society. And this ad hoc methodology also depends on the capacity to introduce and manage the change. In the Nancy area, the evolution of the viewpoint of certain technicians on the role of the inhabitants [13] and the plebiscite of new modes of interactions establish the beginnings of an approach more collaborative in a local ecosystem.

\section{CONCLUSION}

In these works, we met the challenges of the crossed acculturation, the iterative approach, while juggling with the various temporalities of the projects and the actors. Finally, these researches tend to show that putting the "use" in the center of the reflections and creating the conditions of "the societal appropriation" generate thoughts and actions better connected and more global.

This global reviewing of several studies, which focuses on the same study case, shows that an ad hoc methodology (engineering) was developed by an action-research iteration. Technological transfer process is implemented from industrial engineering to urban project design; nevertheless it is essential to consider Human factors (soft skills of local authority's technicians, stakeholder management in participatory process, etc.)

Since 2011, "La Fabrique" experimentation has generated the participatory process of an eco-neighborhood project. This local society gets advantage from the research by the improvement of democratic process. Decision-makers and 
Draft - Publised version available at: Dupont L., Morel L., Hubert J., Guidat C., Study case: Living Lab Mode for urban project design. Emergence of an ad hoc methodology through collaborative innovation.

IEEE 20th ICE-International Conference on Concurrent Enterprising, Bergamo, Italy, 23-25 june 2014

http://ieeexplore.ieee.org/lpdocs/epic03/wrapper.htm?arnumber=6871550

technicians adopt a new vision of users' role in co-design process. Furthermore, a variety of actors (technicians, citizens multidisciplinary researchers, etc.) appropriates and enhances this new methodology for early stages of urban projects. In fact, collaborative innovation was created by "La Fabrique" experimentation and this collaborative innovation allows new urban developments and scientific experimentations in the studied ecosystem.

The final purpose of this paper is to exemplify, with one study case, that adopting the Living Lab Mode for an urban project requires considering at least:

- Industrial projects are not urban projects: if industrial approach can inspire methodology, it is necessary to adapt.

- Users of urban projects are citizens, end-users but also technicians and elected representatives of the local authority where the project takes place.

- The timing of project is fundamental. Urban projects are generally developed over a long period. And a certain length of time is necessary to experiment and observe the impacts of the action-research on the urban project co-design.

The research invites to take time to observe the projects over long period. On a generic aspect, this paper illustrates a crossed approach between technological transfer and iterative methodology. This combination reveals the different relevant steps and activities to generate a framework to co-design urban projects with in mind a long-term strategy for the development of a participatory process. The experimentation shows that some adapted approaches allow involving users throughout the design process. This methodology seems to strengthen the collaborative dimension of the design process of urban projects. But it could be interesting to evaluate the real impacts of the participation's origin (institutional or empowerment) and the attitude of the technical and political decision-makers on the Living Lab mode. Furthermore, user's (citizen's) involvement is not the same during the co-design process, and the level of collaboration depends on the objet studied. In diagnosis stage, a consensus on a wide collection of the deliberate and practicable usages is possible. The selection of requirements and the co-design of functional projects can create stress and difference of opinion. An extensive research on the stakeholder management in complex environment could be relevant.

Finally, the new kinds of collaboration developed for the design-process of urban projects may increase the innovative potential of urban ecosystems. For the moment evidences are weak. Future researches on this topic are necessary. Other scientific contributions are expected and scheduled. Indeed, industrial and territorial partnerships are already engaged to tackle both societal and economical issues with citizens and private and public partners.

\section{REFERENCES}

[1] P. Ballon, J. Pierson, and S. Delaere, "Test and experimentation platforms for broadband innovation : examining European practice," in 16th European Regional Conference by the International Telecommunications Society, 2005.

[2] A. Folstad, "Living Labs for innovation and development of information and communication technology : a literature review," Electron. J. Virtual Organ. Networks, vol. 10, pp. 99-131, 2008.

[3] H. Schaffers, "D3.2 CO-LLABS Technical report for WP3," 2009.

[4] A. Staahlbröst, "Forming Future IT - The Living Lab Way of User Involvement," Luleå University of Technology, 2008.

[5] B. Katzy, K. Pawar, and K. . Thoben, "Editorial : a Living Lab Research Agenda," Int. J. Prod. Dev., vol. 17, no. 1/2, pp. 1-7, 2012.

[6] P. Friedrich, A. Karlsson, and M. Federley, "Boundary conditions for successful Urban Living Labs," 2013.

[7] S. Juujärvi and K. Pesso, "Actor Roles in an Urban Living Lab: What Can We Learn from Suurpelto, Finland?,” Technol. Innov. Manag. Rev., no. November 2013: Living Labs, 2013.

[8] L. Dupont, V. Gholipour, L. Morel, J.-C. Bignon, and C. Guidat, "From Urban Concept to Urban Engineering: The Contribution of Distributed Collaborative Design to the Management of Urban Projects," J. Urban Des., vol. 17, no. 2, pp. 255-277, May 2012.

[9] M. Pallot, B. Trousse, B. Senach, and D. Scapin, "Living Lab Research Landscape: From User Centred Design and User Experience towards User Cocreation," in Living Lab Summer School, 2010.

[10] N. Skiba, L. Dupont, L. Morel, and C. Guidat, "A space for innovation process acceleration, supporting collaborative citizens workshops," in Proceedings of the 18th International Conference on Engineering, Technology and Innovation, ICE’2012 “Innovation by Collaboration and Entrepreneurial Partnerships," 2012.

[11] A. Oliveira, "European perspective on User-Driven innovation (Living Lab)," in In Living Labs Seminar, 2011.

[12] L. Dupont, C. Guidat, and L. Morel, "EMA space: a collaborative workspace as collaborative urban ecosystem generator?," in 16th International conference on Concurrent Enterprising (ICE), Collaborative Environments for Sustainable Innovation, 2010.

[13] ERPI, “Concevoir des projets urbains en intégrant l'expertise d'usage : observation et évaluation des apports d'un espace de travail collaboratif pour améliorer la concertation publique," Nancy, France, 2012.

[14] L. Brissel, L. Morel, and L. Dupont, "Contribution to setting up a sustainable learning in an Eco-Neighbourhood development plan based on serious game," in 1IEEE International Technology Management Conference \& 19th International Conference on Engineering, Technology and Innovation, ICE'2013 "Responsible Innovation and Entrepreneurship," 2013.

[15] S. Checkland, P. \& Holwell, "Action Research - Its Nature and Validity," in Information Systems Action Research: An Applied View of Emerging Concepts and Methods, N. Kock, Ed. Laredo, Texas: Springer US, 2007, pp. 3-17.

[16] L. Dupont, "Transfert du génie industriel vers l'ingénierie urbaine: vers une approche collaborative des projets urbains," Nancy-université-INPL, 2009.

[17] N.Skiba, L.Morel, L.Dupont, and C.Guidat, "Modeling of a living lab approach."

[18] J. Heckman and T. Kautz, "Hard evidence on soft skills.," Labour Econ., vol. 19, no. 4, pp. 451-464, Aug. 2012. 